\title{
A ética em O Evangelho Segundo Jesus Cristo, de José Saramago
}

\author{
Cibele Lopresti Costa
}

FERRAZ, S., et al.,orgs. Deuses em poéticas: estudos de literatura e teologia [online]. Belém: UEPA; Campina Grande: EDUEPB, 2008. 364 p. ISBN 978-85-7879-010-3. Available from SciELO Books $<\underline{\text { http://books.scielo.org }>\text {. }}$

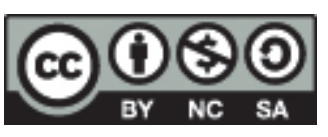

All the contents of this work, except where otherwise noted, is licensed under a Creative Commons Attribution-Non Commercial-ShareAlike 3.0 Unported.

Todo o conteúdo deste trabalho, exceto quando houver ressalva, é publicado sob a licença Creative Commons Atribuição Uso Não Comercial - Partilha nos Mesmos Termos 3.0 Não adaptada.

Todo el contenido de esta obra, excepto donde se indique lo contrario, está bajo licencia de la licencia Creative Commons Reconocimento-NoComercial-CompartirIgual 3.0 Unported. 


\section{A ética em O Evangelbo Se- gundo Jesus Cristo, de José Saramago}

Cibele Lopresti Costa 


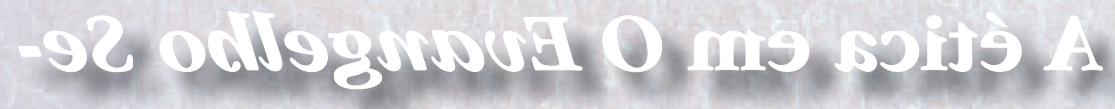

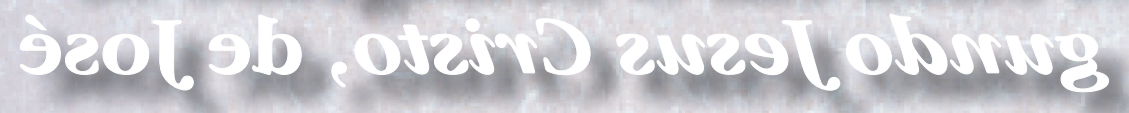
ogumistise

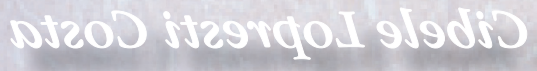


COSTA, Cibele Lopresti*

Resumo: A leitura de O Evangelbo SegundoJesus Cristo, de José Saramago, sugere a reflexão sobre a construção da personagem Jesus que antecipadamente traz em si uma herança religiosa. Esse estudo torna-se pertinente, pois ele é ressignificado na voz do narrador contemporâneo: perde a sacralidade bíblica e se constrói à imagem daquilo que é humanamente possível. Assim, o ponto de vista do narrador favorece a seguinte reflexão: o que ela - personagem Jesus - revela em seu ponto de vista que é do âmbito do sagrado, do religioso, segundo o texto bíblico? E o que é próprio da natureza humana? E, ainda, que valor humano apresentado pela narrativa coincide com os valores apresentados na figura bíblica de Jesus? Esta reflexão tem por objetivo pensar na universalidade e pertinência dos valores apontados pelo narrador para que se possa dimensionar a possível contribuição da Literatura para a construção de valores éticos na contemporaneidade.

Palavras-chave: Saramago, narrador, personagem, sagrado, ética.

Abstract: The reading of The Gospel according to Jesus Christ, by José Saramago, calls for thought on the construction of the character Jesus, who carries in himself a pre-established religious inheritance. This study becomes relevant since Jesus acquires a new meaning in the voice of the contemporary narrator: losing his biblical holiness, he is built in the likeness of the humanly possible. The narrator's point of view thereby evokes the questions: according to the biblical text, what does the character Jesus show, in his point of view, that belongs to the realm of the sacred, of the religious? And what belongs to human nature? And, still, which human value presented by the narrative coincides with the values presented in the biblical figure of Jesus? These considerations seek to evaluate the universality and relevance of the values established by the narrator in order to allow the assessment of Literature's contribution to the ethical construction of values in the contemporary age.

Keywords: Saramago, narrator, character, the sacred, ethics.

* Mestre em Literatura pela UFSC (Universidade Federal de Santa Catarina) na linha pesquisa de Teologia e Literatura. E-mail: nanereis@hotmail.com. 


\section{Introdução}

As primeiras linhas de O Evangelho Segundo Jesus Cristo, de José Saramago, surpreendem pela força imagética do texto. O narrador descreve a cena em que há o contraste entre a luz do sol e a dor presente na expressão do rosto de um homem. O leitor já sabe do que se trata, pois o título já antecipou a principal informação. É a figura sofrida de Jesus no momento da crucificação.

O sol mostra-se num dos cantos superiores do rectângulo, o que se encontra à esquerda de quem olha, representando, o astro-rei, uma cabeça de homem donde jorram raios de aguda luz e sinuosas labaredas, tal uma rosa-dos-ventos indecisa sobre a direcção dos lugares para onde quer apontar, e essa cabeça tem um rosto que chora, crispado de uma dor que não remite, lançando pela boca aberta um grito que não poderemos ouvir, pois nenhuma destas coisas é real, o que temos diante de nós é papel e tinta, mais nada. (ESJC, 2000, p.13).

Tem-se, na imagem, a representação da dor daquele que morreu pela humanidade, segundo os preceitos do catolicismo. Entretanto, ao dizer que nada é real, o narrador aponta para uma possível reflexão: o que se apresenta como singular nesta narrativa? Ou, ainda, o que foi recuperado pelo narrador do romance em questão do texto bíblico sobre Jesus?

O ponto de partida para a análise que segue é a constatação de que o desfecho para a história é a mesma: a crucificação. Assim, sabe-se antecipadamente que o narrador intencionalmente mantém a trajetória da personagem e que seu destino é a morte. Entretanto, sabe-se também que a obra é um objeto literário e não sagrado, tornando a leitura instigante, já que o leitor passa a buscar o viés singular apresentado pela voz narrativa. Cabe ao leitor identificar as dissonâncias e as ressonâncias do texto sagrado no evangelho literário de Saramago. 


\section{A dessacralização}

Frye, em seu livro O código dos códigos, apresenta um interessante estudo a respeito da Bíblia. Logo na introdução, revela as possíveis direções utilizadas para seu estudo. Segundo o autor, a abordagem que se tem feito a respeito do texto bíblico dá-se sob dois vieses: a crítica que estuda o pano de fundo histórico e cultural para seu surgimento e a tradicional, que observa os aspectos teológicos e eclesiásticos de seu significado. Entretanto, ele propõe uma outra, a crítica feita a partir da análise dos textos que, reunidos, formam isso que chamamos de Bíblia, já que ela é a comunhão de várias escrituras. Afirma ele:

Isto levaria a um estudo integrado deste Livro da Bíblia, talvez de toda a Bíblia, como a que se conhece hoje, tendo como êmulo a pergunta sobre por que essa Bíblia emergiu com essa forma particular e não outra. Com toda a miscelânea de seu conteúdo, a Bíblia não parece ter ganho existência através de uma série improvável de acasos; conquanto seja o produto final de um processo editorial muito longo e complexo, esse produto deve ser examinado à luz de sua própria existência.(Frye, 2006, p. 16)

Nessa perspectiva, a leitura da Bíblia favorece a formulação de outra análise que leva o leitor ao reconhecimento de um conjunto híbrido de vozes e a alegorias, à imagética e à polissemia. Assim há a aproximação entre o texto bíblico e a literatura. Logo, a possibilidade de considerá-lo literatura amplia sua leitura, pois o foco de análise se volta para o que não está dito, mas está escondido no jogo de imagens. Ele é a sombra do que se quer dizer, uma possibilidade entre tantas.

Ao considerá-lo texto literário, há uma importante mudança de paradigma. O leitor dos evangelhos deixa de buscar o apaziguamento espiritual e passa a procurar o encantamento próprio que reside nas histórias bem contadas. Ou seja, o leitor cai na armadilha do contador de histórias que não dispõem de fatos comprováveis, mas de linguagem. E, aos moldes dos evangelhos presentes no texto sagrado, o narrador do $E S J C^{93}$ faz sua versão dos fatos, atualizando a história de Jesus, desde seu nascimento até a morte.

O narrador do evangelho saramaguiano demonstra ter conhe-

93 A seguir, o romance analisado será chamado de ESJC. 
cimento do texto bíblico, pois recupera os fatos lá registrados e - ao estabelecer novo ponto de vista - amplia o caráter polissêmico da obra. Esse novo foco sugere possibilidades inéditas de leitura, já que agora se apresenta uma possível versão do protagonista da história. A narrativa em terceira pessoa apresenta detalhes sobre a personagem central, pois já pôde ler a todos os outros evangelhos e contextualizar as conseqüências provocadas pela sua trajetória. O hibridismo aqui presente se delineia na coexistência dos discursos histórico, eclesiástico, científico e literário.

O seu nome também é Maria, segunda na ordem de apresentação, mas, sem dúvida, primeiríssima na importância, se algo significa o lugar central que ocupa na região inferior da composição. Tirando o rosto lacrimoso e as mãos desfalecidas, nada se lhe alcança a ver o corpo, coberto pelas pregas múltiplas do manto e da túnica, cingida na cintura por um cordão cuja aspereza se adivinha. É mais idosa do que a outra Maria, e esta é uma boa razão, provavelmente, mas não é a única, para que a sua auréola tenha um desenho mais complexo, assim, pelo menos, se acharia autorizado a pensar quem, não dispondo de informações precisas acerca das precedências, patentes e hierarquias em vigor neste mundo, estivesse obrigado a formular opinião. Porém, tendo em conta o grau de divulgação, operada por artes maiores e menores, destas iconografias, só um habitante doutro planeta, supondo que nele não se houvesse repetido outra vez, ou mesmo estreado, este drama, só esse em verdade inimaginável ser ignoraria que a afligida mulher é a viúva de um carpinteiro chamado José(...). (ESJC, 2000, p. 15)

O tom irônico usado no fragmento acima, ao citar o leitor desconhecedor dos fatos, sugere uma importante singularidade da obra aqui estudada. Se tudo já se sabe, nada mais há que se contar, entretanto, há uma nova forma de fazê-lo. A novidade do ESJC está na voz do narrador contemporâneo que modifica o tom eclesiástico, seleciona fatos a serem relatados e dá voz aos sentimentos da personagem Jesus.

A dessacralização da personagem central se realiza na ampliação dos discursos que coexistem na voz do narrador. Eles contribuem para a construção de uma nova versão para a trajetória da personagem 
retratada na perspectiva de sua humanidade. A narrativa agrega conhecimentos da ciência, das artes e da história para compor a tradução moderna das experiências relatadas. Nessa composição há a novidade que provoca estranhamento. A coexistência de um novo ponto de vista sobre a história conhecida e da linguagem do narrador tornam a obra inédita e reveladora. $O$ efeito provocado no ato da leitura pode ser o disparador para uma inédita experiência, aquela que leva o leitor à reflexão ou ao choque. Portanto, seu caráter epifânico está presente na representação de um Jesus que busca sua humanidade, já que ele se afasta da conduta reflexiva da meditação e assume a possibilidade de viver experiências terrenas, concretas a fim de encontrar respostas a sua angústia existencial. Assim, a trajetória da personagem leva o leitor a criar analogias com suas próprias experiências.

\section{A materialização}

A história contada no livro passa a retratar a vida de Jesus que procura sua origem, sua razão de viver e a causa para seus males. E em vez de encontrar a voz salvadora e sagrada do Pai, ele encontra a perdição. Percebe-se condenado ao sofrimento provocado pela ação impensada do pai biológico e pelo desejo de poder do pai espiritual. Deus é representado por uma personagem obstinada em deter o poder perpétuo sobre todos os homens e anuncia a Jesus que quer usá-lo como instrumento para a obtenção de seu objetivo.

A desilusão pela qual passa a personagem Jesus espelha a angústia vivida pelo homem na contemporaneidade. As perguntas lançadas pelo narrador no romance saramaguiano são as nossas perguntas. Por que temos que viver a barbárie? Quem há de nos salvar se nem mesmo Deus irá nos salvar nesse instante? Que caminhos devemos seguir se a solidão persiste? Que ética nos guiará?

O filho de José e de Maria nasceu como todos os filhos dos homens, sujo do sangue de sua mãe, viscoso das suas mucosidades e sofrendo em silêncio. Chorou porque o fizeram chorar, e chorará por esse mesmo e único motivo. (ESJC, 2000, p.83)

A natureza da personagem é humana. Ele nasceu do corpo de sua mãe a também tem um corpo. As palavras viscoso e mucosidades materializam sinestesicamente o corpo de Jesus. Ele é humano e não divino, pois revela sua qualidade humana ao agir no mundo e se afasta da caracterização sagrada apresentada nos evangelhos bíblicos. O 
tempo contínuo expresso pelo gerúndio sofrendo revela o movimento constante da dor. Os tempos pretérito e futuro no mesmo enunciado - chorou, chorará - dão constância a sua história. Ao engendrar o nascimento de Jesus na teia dessas escolhas lexicais e sintáticas, o narrador faz também a rede que capta o leitor em sua armadilha. Se nascemos todos do mesmo jeito, se somos filhos da mesma carne e da mesma terra, estamos fadados à mesma trajetória.

Ao leitor desavisado parece não haver saída. Ao longo do romance, o narrador apresenta, na voz de Deus, a antecipação do sofrimento pelo qual Jesus irá passar. Metaforicamente é também o sofrimento vivido pela humanidade:

Deus inspirou profundamente, olhou em redor o nevoeiro e murmurou, no tom de quem acaba de fazer uma descoberta inesperada e curiosa, Não o tinha pensado, isto aqui é como estar no deserto. Virou os olhos para Jesus, fez uma longa pausa, e depois, como quem se resigna ao inevitável, começou, A insatisfação, meu filho, foi posta no coração dos homens pelo Deus que os criou, falo de mim, claro está, mas essa insatisfação, como todo o mais que os fez à minha imagem e semelhança, fui eu buscá-la aonde ela estava, ao meu próprio coração, e o tempo que desde então passou não a fez desvanecer, pelo contrário, posso dizer-te, até, que o mesmo tempo a tornou mais forte, mais urgente, mais exigente. (ESJC, 2000, p.369)

O caráter dramático da narrativa se constrói na desilusão da personagem Jesus frente à filiação. Não há pai que o salve dessa infinita tristeza. A morte do pai biológico deixou-lhe uma triste herança, um sonho recorrente que sugere a responsabilidade de uns frente à morte de outros. Na repetição do sonho, há a presença da dúvida quanto ao agir frente às coisas do mundo. Ao morrer, o progenitor despertou na mente do filho a consciência sobre a responsabilidade do homem frente à morte ou salvação, ou melhor, sobre o comprometimento que há entre os habitantes da Terra.

Quanto ao pai espiritual, a desilusão permanece. Esse pai revela que ele mesmo plantou no coração dos homens a insatisfação. Outra herança dolorosa. Ele - Jesus - nada pode esperar da transcendência. Nem mesmo na transcendência do Criador há a mão que o pode salvar da angústia. A trajetória de sua vida passa a ser uma aventura desco- 
nhecida.

O romance se materializa como objeto de transgressão aos evangelhos bíblicos. A narrativa concretiza as experiências filosóficas vivenciadas pelos homens na contemporaneidade, daqueles que já se desiludiram de Deus e da salvação divina. E aponta também para a direção de outros caminhos para a salvação. A personagem Jesus encontra o amor ao conhecer Maria de Magdala. Apropria-se de seu corpo e permite que seu braço seja o amparo dela e que o braço dela seja seu amparo. $\mathrm{E}$ assim vivificam a unidade desejada, transcendem à dor terrena e encontram a paz, mesmo que momentânea. O corpo passa a ser objeto de descoberta. A linguagem do narrador favorece esse encontro e há o apaziguamento das emoções.

Não te prenderás a mim pelo que te ensinei, mas fica comigo esta noite. E Jesus sobre ela, respondeu. O que me ensinas, não é prisão, é liberdade. (...) Fala-me da tua vida, mas agora não só quero que a tua mão esquerda descanse sobre a minha cabeça e a tua direita me abrace. (ESJC, 2000, p.284)

Assim, a narrativa aponta para novas possibilidades de salvação. E o leitor se dá conta da forma singular desse evangelho e de suas pistas para novos rumos frente ao conflito humano.

\section{Escolhas}

Se por um lado, a orfandade retratada no romance de Saramago leva o leitor à experiência amarga do abandono, há outra possibilidade. O narrador reconta os passos de Jesus anteriores à crucificação, transgredindo o caráter religioso, pois usa a linguagem como instrumento de vivificação de suas características humanas. O narrador (re)conta a história tornando a personagem especial pelo agir, pelo seu modo dessacralizado de viver. Na passagem da multiplicação dos peixes, há o relato da incerteza vivida pelo protagonista e, ainda, sua ação a favor da sobrevivência:

Que o Senhor esteja consigo, não o duvida Jesus, pois o peixe nunca deixa de vir quando o chamar, e esta circunstância, por um processo dedutivo inevitável de que aqui não julgamos necessário fazer a demonstração e apresentar a seqüência, 
acabou por levá-lo, com o tempo, a perguntar-se se não haveria acaso outros poderes que o Senhor estivesse disposto a ceder-lhe, não por delegação ou outorga, claro está, apenas emprestados, e com a condição de fazer deles bom uso, o que, como temos visto, Jesus estava em condições de garantir, haja vista o trabalho a que meteu ombros, sem mais que a intuição a ajudá-lo. A maneira de saber era fácil, tão fácil como dizer ai, bastava fazer a experiência, se ela resultasse, era porque Deus estava a favor, se não resultasse, Deus manifestava que estava contra. Simplesmente, havia uma questão prévia a resolver, e essa questão era a escolha. Não sendo possível consultar directamente o Senhor, Jesus teria de arriscar, seleccionar entre os poderes possíveis o que parecesse oferecer menos resistência e que não desse demasiado nas vistas, porém não tão discreto que passasse despercebido a quem dele viesse a beneficiar e ao mundo, com o que padeceria a glória do Senhor, que em tudo deve prevalecer. (ESJC, 2000, p. 333-334)

A passagem acima espelha a visão que se constrói sobre a personagem Jesus. Ele já sabia que seu destino seria a morte escolhida pelo Pai, reconhecia-se impotente frente a esse fato. Não encontrava auxílio ou apoio Nele. Assim, resolve agir para sobreviver à tormenta da adversidade. E experimenta simplesmente. Segundo o narrador, o milagre da multiplicação dos peixes é fruto de uma tentativa e não de uma certeza. E Jesus assume uma atitude humana: frente à adversidade, arrisca-se.

O narrador destaca, com alguma ironia, que havia 'uma questão prévia a resolver, e essa questão era a escolha'. Significativa passagem essa que retira de Deus o poder de decidir sobre o destino de outrem e traz para o protagonista a decisão sobre sua própria vida. Por meio de suas escolhas, a personagem passa a experimentar os acontecimentos do mundo e não se priva de distinguir-se do Pai. Enfrenta a aventura desconhecida rumo à morte sem abster-se de viver o que lhe é de direito: também não quer passar despercebido. A transgressão reside no ponto de vista da história, mas também na dessacralização da linguagem utilizada para contar o que já está registrado no texto bíblico. 


\section{Itinerâncias do Nada}

Segundo Edgar, Morin, em seu livro Terra-Pátria, a consciência da morte nos leva a uma condenação prévia, a um eterno estado de finitude, a "viver entre nada e nada, o nada de antes, o nada de depois, cercados de nada durante". E continua representando o ato de viver como "itinerância", um caminhar que se inicia no nascimento e pressupõe a morte. Embora pareça um caminho desalentador, o autor oferece uma saída:

Estamos na aventura desconhecida. A insatisfação que faz recomeçar a itinerância jamais poderia ser saciada por esta. Devemos assumir a incerteza e a inquietude, devemos assumir o dasein, o fato de estar aí sem saber por quê. Cada vez mais haverá fontes de angústia e cada vez mais haverá necessidade de participação, de fervor, de fraternidade, os únicos que sabem, não aniquilar, mas rechaçar a angústia. $O$ amor é o antídoto, a réplica - não a resposta - à angústia. É a experiência fundamentalmente positiva do ser humano, em que a comunhão, a exaltação de si, do outro, são levados ao seu melhor, quando não se alteraram pela possessividade. Será que não se poderia degelar a enorme quantidade de amor petrificado em religiões e abstrações, votá-lo não mais ao imortal, mas ao mortal? (Morin, Kern, 2000, p. 178)

A proposta de Morin para a contemporaneidade parece condizer com a apresentada no romance em questão. As duas apresentam uma saída para a perdição em que se encontra a humanidade, ou seja, sugerem a busca de um novo procedimento ético. Observemos como a proposta se configura no romance:

Jesus morre, morre, e já o vai deixando a vida, quando de súbito o céu por cima da sua cabeça se abre de par em par e Deus aparece, vestido como estivera na barca, e a sua voz ressoa por toda a terra, dizendo, Tu és o meu Filho muito amado, em ti pus toda a minha complacência. Então Jesus compreendeu que viera trazido ao engano como se leva o cordeiro ao sacrifício, que a sua vida fora traçada para morrer assim desde o princípio dos princípios, e, subindo-lhe à lembrança o rio de 
sangue e de sofrimento que do seu lado irá nascer e alagar toda a terra, clamou para o céu aberto onde Deus sorria, Homens, perdoai-lhe, porque ele não sabe o que fez. Depois, foi morrendo no meio de um sonho, estava em Nazaré e ouvia o pai dizer-lhe, encolhendo os ombros e sorrindo também, Nem eu posso fazer-lhe todas as perguntas, nem tu podes dar-lhes todas as respostas.(...). (ESJC, 2000, p.444)

O sentido expresso por Morin de existência - dasein - carrega em si a expressão de Heidegger, o sentido de finitude inerente à experiência. Saramago, ao iniciar sua obra com a descrição da cena da crucificação, transforma em Literatura as idéias discutidas nos escritos dos filósofos citados - e também de seus antecessores. E, carregando em si a natureza transgressora da arte, modifica o paradigma da tradição religiosa, transferindo o caráter sagrado das decisões de Deus para o agir humano.

Sabe-se inicialmente que a vida é finita e que o destino da personagem Jesus é o conhecido, entretanto, há nela uma nova ética, pois ele aceita sua condenação e, serenamente, passa a habitar a Terra como quem passa por uma experiência. E o narrador saramaguiano usa a linguagem literária para singularizá-la. Nela, Jesus passa a viver o "habitar poético" citado por Benedito Nunes: "a instauração poética pela palavra regeria o construir, no sentido do trato da terra para erigir a habitação humana". (2007, p.151)

O novo ponto de vista sobre a história de Jesus, no ESJC, é revelado pela linguagem e (não)ação da personagem, já que tudo é ficção previamente revelada pelo narrador: "O que temos diante de nós é papel e tinta, mais nada.” $(E S J C, 2000$, p. 13). Portanto, há dois vieses sugeridos na construção de uma nova ética neste romance. O primeiro diz respeito à linguagem. A quebra da sintaxe, o uso de ironias e também a presença do lirismo na narrativa sugerem uma possível saída para a angústia vivida na contemporaneidade. A linguagem que aproxima e não define sentidos, que relaciona e não generaliza, que sugere e não fecha sentidos, poderia ocupar as fendas deixadas por aqueles que denunciaram a finitude do ser.

O segundo refere-se ao agir da personagem. Ao aceitar os erros de seu Pai, ao permitir que ele tomasse posse do poder desejado, ao permitir que se concretizasse o plano divino, ele revela um procedimento difícil de ser imaginado em meio à barbárie, entretanto possível. 
Ele O perdoa. E aponta para uma possível atitude de resistência frente a nossa perdição. $\mathrm{O}$ perdão.

Assim, pode haver um caminho para a construção de uma ética na contemporaneidade. Um agir que não depende de ação, mas de transformação interior, de consciência de si e das relações de si com o mundo. Da compreensão do outro em si. A ética que resiste à barbárie, pois faz do homem consciência de sua impermanência, de sua finitude e de sua imperfeição. 


\section{Referências}

FRYE, Northorp. O código dos códigos. São Paulo: Boitempo Editoral, $2^{\mathrm{a}}$ edição, 2006.

MORIN, Edgar. O método 6 - ÉTICA. Porto Alegre: Editora Sulina.

MORIN, Edgar, KERN, Anne Brigitte. Terra-Pátria. Porto Alegre: Editora Sulina, $3^{\text {a }}$ edição, 2000.

NUNES, Benedito. Hermenêutica e Poesia. Belo Horizonte: Editora UFMG, 2007.

SARAMAGO. José. O Evangelho Segundo Jesus Cristo. São Paulo: Companhia das Letras, 2000. 